\title{
Corrigendum: Comparative evaluation of DNase-seq footprint identification strategies
}

\author{
Iros Barozzi ${ }^{1}$, Pranami Bora ${ }^{2}$ and Marco J. Morelli ${ }^{2 *}$ \\ ${ }^{1}$ Department of Experimental Oncology, European Institute of Oncology, Milan, Italy \\ ${ }^{2}$ Center for Genomic Science of IIT@SEMM, Fondazione Istituto Italiano di Tecnologia (IIT), Milan, Italy \\ *Correspondence: marco.morelli@iit.it
}

Edited and reviewed by:

Mark D. Robinson, University of Zurich, Switzerland

Keywords: DNase-seq, footprinting, gene regulatory networks, bioinformatics tools and databases, comparison of methods

\section{A commentary on}

Comparative evaluation of DNase-seq footprint identification strategies

by Barozzi, I., Bora, P., and Morelli, M. J. (2014). Front. Genet. 5:278. doi: 10.3389/fgene.2014.00278

Figure 1 of the article Comparative evaluation of DNase-seq footprint identification strategies, by Barozzi et al. (2014) contained a minor mistake, which we correct here. In panel $\mathrm{E}$, the $\mathrm{y}$ axis ranges from 0.5 to 1 and not from 0 to 1 as indicated in the original figure. We resubmit a corrected version of Figure 1.

\section{REFERENCES}

Barozzi, I., Bora, P., and Morelli, M. J. (2014). Comparative evaluation of DNase-seq footprint identification strategies. Front. Genet. 5:278. doi: 10.3389/fgene.2014.00278

Conflict of Interest Statement: The authors declare that the research was conducted in the absence of any commercial or financial relationships that could be construed as a potential conflict of interest.

Received: 26 August 2014; accepted: 26 August 2014; published online: 19 September 2014.
Citation: Barozzi I, Bora P and Morelli MJ (2014) Corrigendum: Comparative evaluation of DNase-seq footprint identification strategies. Front. Genet. 5:320. doi: 10.3389/fgene.2014.00320

This article was submitted to Bioinformatics and Computational Biology, a section of the journal Frontiers in Genetics.

Copyright () 2014 Barozzi, Bora and Morelli. This is an open-access article distributed under the terms of the Creative Commons Attribution License (CC BY).

The use, distribution or reproduction in other forums is permitted, provided the original author(s) or licensor are credited and that the original publication in this journal is cited, in accordance with accepted academic practice. No use, distribution or reproduction is permitted which does not comply with these terms. 

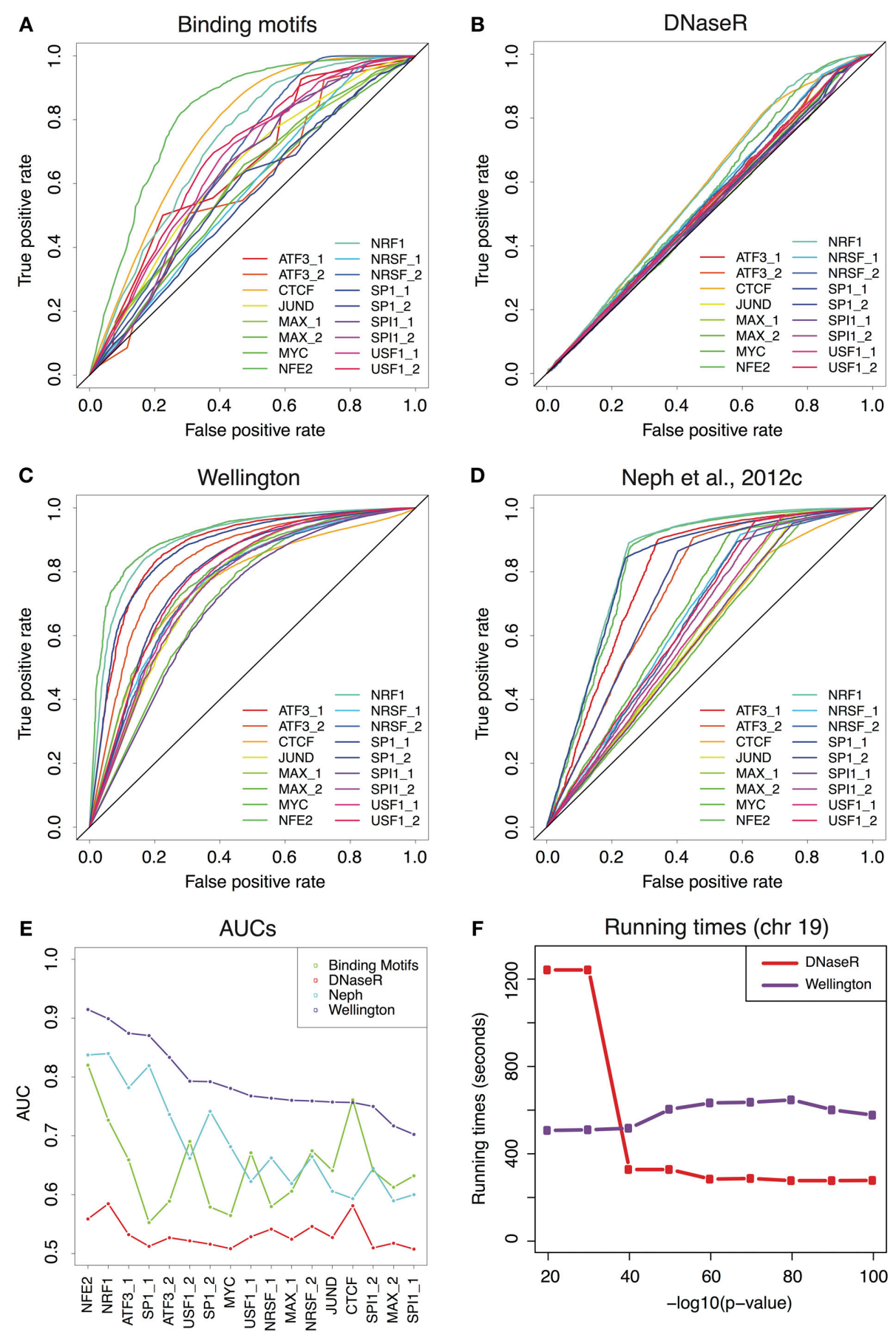

FIGURE 1 | (A) Receiver-Operator Characteristic (ROC) curves for the predictions provided by the binding motifs alone. (B-D) ROCs for the sets of footprints obtained by DNaseR, Wellington and for the set used in Neph et al.(2012c). (E) Area Under the Curve (AUC) corresponding to the ROCs of (A-D) Wellington scores consistently better than all theother methods. (F) Running times for DNaseR and Wellington on chromosome19, for different significance thresholds. 